\title{
Teaching and Learning Strategies to Accommodate All Students at a University of Technology \\ Prof Kholeka Constance Moloi
}

\author{
Vaal University of Technology, Faculty of Human Sciences \\ Vanderbijlpark, South Africa \\ Email:conniem@vut.ac.za
}

Ms Mamohale Dimema

Vaal University of Technology, Research Directorate

Vanderbijpark, South Africa

Email:mamohale@vut.ac.za

Doi:10.5901/mjss.2014.v5n3p493

\begin{abstract}
There are many challenges facing university education in South Africa. Despite the transformation efforts to improve the quality of education, the system continues to produce inequalities in terms of class, gender and race as well as access to higher education. For many of the students who have access to higher education, particularly those who emerge from the previously disenfranchised black communities, academic achievement and learning success are problematic. This is due to, among other factors, insufficient preparation for learning, lack of adequate English language competence, socio-economic background and other social burdens, including poverty. It is against this backdrop that this article explores teaching and learning strategies that can be employed to accommodate all students despite their social, economic, political and intellectual backgrounds. Use is made of different theories to locate our arguments. We argue that teachers are able to mediate student learning if we collaborate with and engage our students in the learning processes.
\end{abstract}

Keywords: Constructivism, ICT facilitated learning environments, actively engaged learning, social learning, individual learning

\section{Introduction}

The rapid growth in information on effective and innovative teaching and learning and the increasing proliferation of electronic sources pose a number of challenges in how we think about and execute the scholarship of teaching and learning (Murray 2008:46). Given that the university is a knowledge industry that has a tremendous influence on many people, if it is to have any credibility in the public sphere it must recognise that teachers play a crucial role in shaping the identities, values and beliefs of students (Giroux 1997:152). Using the principles of a learner-centred and learningcentred approach ensures that all students are at the centre of the learning experience, control their own learning, assume responsibility for learning, initiate learning goals and regulate their performance in achieving these goals (Jonassen, Marra \& Palmer 2004:75). This means that we need to create rich environments for active learning (REALs). These environments are instructional systems that engage learners in realistic, authentic, complex, and information-rich learning contexts; support intentional, self-regulated learning; support co-operative learning efforts in learning; and engage learners in complex problem solving to anchor meaning-making (D'Andrea \& Gosling 2005:133).

We agree with D'Andrea \& Gosling (2005:80) that learning is both a social and an individual process that requires the social context in which learning is taking place and the impact it has on individual performance. Research indicates that learning is a voluntary activity, and each learner comes to learning with his or her own understandings, culture, values, social relationships, assumptions, learning preferences and motivations (Doyle \& Singh 2006). Thus, knowledge, understanding and skills are negotiated and developed in a social setting - through interacting with peers, information, lecturers and the broader community (Robbins, Judge, Odendaal \& Roodt 2009). We ask ourselves: what teaching and learning strategies can we use to accommodate learning needs of diverse learners, and how do we plan the curriculum of the specific subjects that we teach, the learning methods and knowledge production in order to accommodate all learners? These and many more questions unsettle our minds as we ponder how best we can educate all learners. Our 
quest is to ensure that the student learning experience is provided within a learner- and learning-centred, rich, technology-enhanced learning environment, where pedagogical content knowledge is driven by inter-, intra- and multidisciplinary perspectives that will enable our students to critically examine their transformative roles in society as concerned citizens (Doyle \& Singh 2006:3).

\section{Gardner's Theory of Seven Intelligences}

Gardner's (1999) theory of seven intelligences is useful as a framework within which to locate our discussion. The seven intelligences are critical in providing an understanding of how best to accomplish our teaching and learning and which methods will best enable us to address the learning needs of all students. According to Gardner, the first two have been typically valued in schools; the next three are usually associated with the arts; and the final two are what Howard Gardner called 'personal intelligences' (p. 41-43). These intelligences are described below:

(i) Linguistic intelligence involves sensitivity to spoken and written language, the ability to learn languages and the capacity to use language to accomplish certain goals. This intelligence includes the ability to use language effectively to express oneself rhetorically or poetically and language as a means to remember information. Writers, poets, lawyers and speakers are among those that Howard Gardner sees as having high linguistic intelligence.

(ii) Logical-mathematical intelligence consists of the capacity to analyse problems logically, carry out mathematical operations and investigate issues scientifically. In Howard Gardner's words, it entails the ability to detect patterns, reason deductively and think logically. This intelligence is most often associated with scientific and mathematical thinking.

(iii) Musical intelligence involves skill in the performance, composition and appreciation of musical patterns. It encompasses the capacity to recognise and compose musical pitches, tones, and rhythms. According to Howard Gardner musical intelligence runs in an almost structural parallel to linguistic intelligence.

(iv) Bodily-kinaesthetic intelligence entails the potential of using one's whole body or parts of the body to solve problems. It is the ability to use mental abilities to coordinate bodily movements. Howard Gardner sees mental and physical activity as related.

(v) Spatial intelligence involves the potential to recognise and use the patterns of wide space and more confined areas.

(vi) Interpersonal intelligence is concerned with the capacity to understand the intentions, motivations and desires of other people. It allows people to work effectively with others. Educators, salespeople, religious and political leaders and counsellors all need a well-developed interpersonal intelligence.

(vii) Intrapersonal intelligence entails the capacity to understand oneself, to appreciate one's feelings, fears and motivations. In Howard Gardner's view it involves having an effective working model of ourselves and being able to use such information to regulate our lives.

We believe that a grasp of these different intelligences can assist us in implementing teaching strategies that enable us to accommodate all learners in the classroom.

\section{Teaching Methodologies and Strategies to Accommodate All Students}

In keeping abreast of the latest innovative teaching and learning strategies it is essential that we focus on learning and the application of learning, which means that the practice of teaching must be learner-centred, flexible and meaningful. In following a learner- and learning-centred approach to teaching and learning, we are aware that individual learners have the capacity to reflect on real-life problems, apply knowledge and skills, work with others and find solutions - an important outcome of learning (Louw, Moloi \& Smit 2012:2). We argue that teaching and learning practices should provide opportunities for social learning, place learning in relevant and meaningful contexts, provide supportive learning environments (for example, constructivist learning environments), value and recognise diversity and provide for dynamic engagement and deeper learning. Providing intellectual spaces for deep learning during class lessons, dialogues and discussions involves the steps students must take in the learning process and their ability to articulate their initial knowledge or cultural capital. The teacher should add to what is already known, and refine and enrich it with the student's own efforts. A few teaching and learning strategies to accommodate all learners are discussed below. 


\subsection{Transitional Outcomes-Based Education}

According to Brady (1995:9), transitional OBE moves away from traditional curricula to identify outcomes that reflect higher-order competencies which cut across traditional subjects. Content is used as the vehicle to attain higher-order competencies such as problem solving, critical thinking, effective communication and technological applications, opens doors to curriculum designs and teaching approaches and redefines authentic assessment. An integration-across-thecurriculum approach is adhered to. It is adapted to both the curriculum and the learner and there is a measure of interaction between the learner and teacher. Thus, transitional OBE also deals with the question: 'Why do learners need to know this?' It focuses on the qualities learners will need to operate competently in a competitive society (DoE 1997:18).

\subsection{Transformational Outcomes-Based Education}

Transformational OBE is the most sophisticated evolution of the outcomes-based concept. It moves away from the traditional curriculum. Curriculum development and resource allocation reflect the scope and nature of the outcomes. The curriculum is designed by starting with future-driven outcomes. The intention is to equip all learners with the knowledge, competence and orientation needed for success after they leave school (Brady 1995:9). Transformational OBE requires that the learner and the curriculum be totally integrated with a view to giving meaning to the latter. It is also characterised by strong humanistic and social adaptation, as well as a high level of involvement by both the teacher and the learner (Olivier 1998:57). Spady (1994:63-64) asserts that with transformational OBE, the question that arises is: what sort of qualities, both as workers and as human beings, would be expected of citizens? This outcome becomes even more important than in transitional OBE. In this teaching and learning approach, learning outcomes, which include the knowledge, skills and attitudes that citizens will need to function as critical, engaged citizens, become the only determinants of the curriculum.

\subsection{Open Learning environments (OELEs)}

Open-ended learning environments (OELEs) stress the use of manipulable objects to support experiential learning and student model building. OELEs provide rich contexts, friendly interfaces, manipulation tools, supporting resources and guidance to facilitate learner understanding. They support identifying, questioning and testing personal models of phenomena as learners develop theories-in-use (Jonassen et al. 2004:75). In goal-based scenarios (GBSs), students become active participants in complex systems. They employ a 'learning by doing' architecture in which learners are immersed in a focused, goal-oriented situation and are required to perform authentic, real-world activities. They are supported with advice in the form of stories that help students learn the language of the discipline.

\subsection{ICT-enhanced learning environments}

Research by Shelly, Gunter \& Gunter (2010:1) indicates that in the classroom, computers and computer-related technologies have a profound influence on how we instruct and how students learn. D'Andrea and Gosling (2005:134) pose the following question: 'Are pedagogically led centres a helpful structure for implementing learning technologies?' They cite a study conducted in the UK which showed that eight universities that introduced and implemented learning technologies had a greater chance of succeeding in engaging faculty/staff with learning technologies for improving teaching and learning. It is essential that ICT be integrated in the various discipline-specific curricula because we are educating students who live and will work in a technology-rich global society. The knowledge and skills they acquire through our modified teaching strategies will enable them to be successful and productive citizens in a technology-driven economy and knowledge society. The integration of knowledge that we gain in ICT-enhanced learning can be used in different ways, including for personal professional development, using technology as a productivity tool in the lecture hall, and extensively integrating technology and digital media in instructional strategies, lessons, student-based projects and student assessments to improve student learning. Furthermore, D'Andrea and Gosling (2005:134) point to numerous benefits of using modern learning technologies, for example:

- Greater interactivity with learning materials (with or without a teacher);

- Asynchronous learning from multiple sites;

- Increased flexibility in location of learning; and 
- Increased access to a wide range of search tools and resources for learning.

While the locus of leadership for bringing a new learning technology into higher education has been highly contested both by those with pedagogical expertise and those with technological expertise (D'Andrea and Gosling 2005:134), it is essential that teachers are involved in curriculum-specific learning or discipline-specific learning, which is learning how to apply teaching principles, knowledge, and ideas to authentic and practical lessons and projects that can benefit our students.

\subsection{Individual learning}

Individual learning is self-directed and self-paced learning (Duffy \&Kirkley 2004:8). Self-directed learning has been described as a process in which individuals take the initiative, with or without the help of others, to diagnose their learning needs, formulate learning goals, identify resources for learning, select and implement learning strategies, and evaluate learning outcomes (Knowles 1975). Whether learning is self-directed or not does not depend on the subject matter or the methods used. Instead, self-directedness depends on who is in charge, who decides what should be learned, who should learn it, what methods and resources should be used, and how the success of the effort should be measured. To the extent that the learner makes those decisions, the learning is generally considered to be self-directed. An estimated 70 percent of adult learning is self-directed learning (Cross 1981). One of the aims of PBL is the development of selfdirected learning (SDL) skills. In the discussion by Loyens, Magda \& Rikers (2008), SDL is defined as a process in which individuals take the initiative in diagnosing their learning needs, formulating goals, identifying human and material resources, choosing and implementing appropriate learning strategies and evaluating learning outcomes. By being invited into the learning process, students are also invited to take responsibility for their learning, which leads to an increase in self-directed learning skills. Thus an understanding and consideration of adult learning principles (andragogy) is essential if we are to be successful in self-directed learning.

\subsection{Constructivist learning style}

As has been alluded to elsewhere in this paper, learning has a socially situated character, and it should be embedded in real-life situations in order to provide a holistic perspective that enables a connection between theory and practice. In this regard, the theory of constructivism is focussed on the world inside the learner. Constructivists believe that reality is determined by the senses of the knower (Rothwell 2002:51). In constructivism individuals construct knowledge through interactions with the environment. Constructivism takes the idea of interconnectedness between learner and the environment to its logical limits. Here the idea is that the environment influences internal processes, but at the same time, those same internal processes influence the environment. Knowledge is constructed when learners can link new knowledge to their existing conceptual framework, and new meaningful interconnections are constructed that transform existing conceptions. As a result, we create knowledge in our own heads and that created knowledge may be interpreted differently by each of us.

Informed by this approach, we believe that students benefit more from learning that is transformative, which means that knowledge is co-created through their lived experiences, their thoughts and ideas, their voices, their feelings, and perceptions, their values and their culture, as well as how they construct their own social and intellectual identity as active learners and the roles they perform in civil society. Thus, transformative learning can be summarised as a process where students use prior interpretation to construe a new or revised interpretation of the meaning of their experiences in order to guide future action. An individual's acquired frame of reference is central to constructivism. It is through this frame of reference or meaning scheme that all meaning is construed and all learning takes place. Proactive action by the student includes making decisions and associations, revising points of view, reframing or solving problems, modifying attitudes or producing changes in behaviour (Steenekamp, Botha \& Moloi 2012:4).

The guiding principles of constructivism are that learning is a search for meaning and that meaning requires the understanding of wholes as well as parts. The purpose of learning in constructivism is for an individual to construct his or her own meaning, not just to memorise the 'right' answers and to regurgitate somebody else's meaning (Silverthorn, 1999:2-4). Constructivism transforms the learner from a passive recipient of information to an active participant in the learning process (Rothwell 2002:51). The theory of constructivism taps into and triggers the learner's innate curiosity about the world and how things work. Learners do not reinvent the wheel but rather attempt to understand how it turns or how it functions. Learners become actively involved by applying their existing knowledge and real-life experience, testing their theories and drawing conclusions on their findings. For us, university education goes beyond mastering factual 
knowledge into higher-order thinking skills and developing the ability to grapple with real-life problems through creating enabling learning and assessment contexts. We believe that our lecturers should provide epistemological and pedagogical spaces as well as generative learning in order for students to master competences that they will need after graduation. D'Andrea and Gosling (2005:137-138) suggest that to increase the benefit for students from learning, the following strategies could be used:

1. Keep the students learning and practising new things.

Learning and practising new skills helps the brain retain new information. The benefit to students is increased when curriculum and assessment are embedded in activities that they value but that are also valued by other students and the wider culture.

2. Try to encourage multiple ways of learning.

Create learning conditions that will enable students to learn in more than one way. Instead of just listening to a podcast, which involves auditory learning, try to make them rehearse the information both verbally and visually. Sometimes allow them to describe to a friend what they have learned and encourage them to take notes during a lecture and then draw up a mind map so that they have a conceptual model of what is being taught.

3. Encourage team learning.

Learning is a continuous process of reflecting on information and sharing, critiquing and re-thinking learnt information in different ways. This process also helps me to solidify what I have learnt through collaboration, using informal and formal exchanges, as well as sharing ideas and constructive suggestions with my peers and others.

4. Utilise previous learning to promote new learning.

Another great way that I use to increase the benefit from learning is to use relational learning, which involves relating new information to things that I already know. For example, if I am taught about how to develop a learning unit for a particular module, I tend to relate to the modules that are offered in the programme. In other words, I try to find relationships or associations between concepts. This association helps to solidify what I am learning. Understanding entails taking knowledge gained in one setting and using it in another.

5. Encourage students to apply what they are learning.

For me, although learning typically involves reading textbooks, attending lectures or doing research in the library or on the web, seeing information and then writing it down is important, so that I actually put the new knowledge and skills into practice. For me, this is one of the best ways to improve learning and to increase the benefit of the learning experience. I believe that practical experience makes theory and knowledge concrete because I can see, touch, feel, smell, and taste. In so doing I know better because I have 'done' or experienced the learning practically.

6. Allow students look up answers rather than struggle to remember.

With the advancement of technology and multimedia and various modes of learning, we need to encourage students to look up answers on the Internet or in an encyclopaedia. One study found that the longer you spend trying to remember the answer, the more likely you will be to forget the answer again in the future because these attempts to recall previously learned information actually result in learning the 'error state' rather than the correct response (D'Andrea \& Gosling, 2005: 133).

7. Create contexts for individualised learning spaces.

A great strategy for improving learning efficiency is to sensitise students to the ability to recognise their learning habits and styles as well as the places where they learn best. For example, Gardner's theory of multiple intelligences describes seven different types of intelligence that can help reveal an individual student's strengths. Gardner (1999) says: 'I want my children to understand the world, but not just because the world is fascinating and the human mind is curious. I want them to understand it so that they will be positioned to make it a better place. Knowledge is not the same as morality, but we need to understand if we are to avoid past mistakes and move in productive directions. An important part of that understanding is knowing who we are and what we can do... Ultimately, we must synthesize our understandings for ourselves. The performances of understanding that truly matter are the ones we carry out as human beings in an imperfect world which we can affect for good or for ill (Gardner 1999: 180-181).'

8. Use tests and assignments to boost learning.

We believe that tests and assignments are more beneficial for students than studying alone. Research has demonstrated that taking tests and writing assignments actually helps one remember what one has learned, 
even if it was not covered in the test. The study revealed that students who studied and were then tested had better long-term recall of the materials, even on information that was not covered by the tests.

\section{Why is It Important to Accommodate All Learners?}

Accommodations are significant in ascertaining the impact of my teaching strategies. According to Tomlinson (1999) and Winebrenner (1996), these accommodations fall into four major categories.

(i) Content: What the student needs to learn. The instructional concepts should be broad based and all students should be given access to the same core content. However, the content's complexity should be adapted to students' learner profiles. This will allow me to vary the presentation of content (e.g., textbooks, lecture, demonstrations, taped texts) to best meet all my students' needs.

(ii) Process: This involves activities in which the student engages to make sense of or master the content. Examples of differentiating process activities that I use include scaffolding, flexible grouping, interest centres, manipulatives, varying the length of time for a student to master content, and encouraging an advanced learner to pursue a topic in greater depth.

(iii) Products: The products are the culminating projects in which I ask my students to apply and extend what they have learned. I advise students that products should provide them with different ways to demonstrate their knowledge as well as various levels of difficulty, group or individual work, and various means of scoring.

(iv) Learning Environment: This is about the way the classroom works and feels. The differentiated classroom in which we teach includes areas in which students can work quietly as well as collaborate with others and materials that reflect diverse cultures.

These strategies enable us to analyse our students' profiles and to have an observant eye when we interact with them during the teaching and learning process. It may take time to really grasp and understand their individual capabilities and how each one of them learns. However, from the teaching and learning interaction we may be able to identify the different intelligences as explained by Gardner (1999). Therefore, in the attempt to accommodate all learners, our teaching strategies will vary from using inquiry, modelling, collaborative techniques, simulations, brainstorming, problem-based learning (PBL), question-and-answer methods (Socratic dialogue), mind mapping and discovery to the traditional lecture method. For example, three to four of these teaching strategies could be combined in one lesson integrated with learning technologies. We may, for example, start with a traditional lecture method and thereafter pose questions in order to engage the students. This may be followed by a short exercise to solve a problem (PBL) and possibly give them an exercise where they are expected to discover an answer (Chan, McDermott \& Roediger 2007:560).

It is also important that we take cognisance of the socio-economic and political factors, including cultural diversity, that affect the success of diverse students in order to provide a culturally responsive curriculum and pedagogy. The personal and academic relationships between us and the students are the most influential in accommodating all learners. This relationship has been referred to as the 'core relationship' of learning - our teaching role and students, the subject matter, and their interaction in the classroom setting. When accommodations are made, all students benefit. Accommodations do not fundamentally alter or lower expectations or standards in instructional level (conceptual difficulty), content or performance criteria. Instead, changes are made in the instructional delivery method, assessment method or both to enable the student to have access to the same learning and equal opportunity to demonstrate learning-epistemological access (Biggs 1999).

To be able to build a stronger teaching and learning relationship within my diverse classroom to accommodate all learners, the teaching strategies described below will be used. These will also be informed by the lesson objectives and intended learning outcomes.

1. Appreciate and accommodate the similarities and differences among the students' different intelligences and diverse cultures. We believe that effective teachers enthusiastically acknowledge both individual and cultural differences, as well as different intellectual capabilities and identify these differences in a positive manner. This positive identification creates a basis for the development of effective communication and instructional strategies. I can model, teach, prompt and reinforce social skills such as respect and cross-cultural understanding.

2. Build relationships with students. Interviews with students who presented behaviour challenges for me in class reveal that they may have wanted me to discover what their lives are like outside of the institution, for example. Therefore, developing an understanding of students' lives also enables me to increase the relevance 
of lessons and make examples more meaningful (real-life problems).

3. Focus on the ways students learn and observe students to identify their task orientations. Once we know the students' orientations we structure tasks to take them into account. For example, before some students can begin a task, they need time to prepare or attend to details. In this case, we allow time for students to prepare, provide them with advance organisers and announce how much time will be given for preparation and when the task will begin. This is a positive way to honour their need for preparation, rituals or customs.

4. Teach students to match their behaviours to the setting. We all behave differently in different settings. For example, we behave more formally at official ceremonies. Teaching students the differences between their home, institution, and community settings can help them switch to appropriate behaviour for each context. While some students adjust their behaviour automatically, others must be taught and provided with ample opportunities to practise. We believe that involving families and the community can help students learn to adjust their behaviour in each of the teaching and learning settings in which they interact. These teaching strategies are intertwined with how we design instructional strategies, as will be articulated below.

\section{Designing Lessons to Accommodate Diverse Learners}

Given that new technologies provide innumerable tools to design lessons, it is significant that teachers make use of them in designing lessons to accommodate diverse learners, as suggested by Entwistle (1987).

Step 1: We create a plan for adapting materials and support. This must be made within the framework of a larger plan that includes consideration of (a) basic and strategic skills instruction and (b) the roles of people involved in the adaptation process. In some cases, it is important to involve the department's administrator and curriculum or programme coordinator from the beginning and to identify exactly who will be responsible for making, implementing, supporting and evaluating the adaptation over the course of the year. As far as possible, we involve students and other support staff such as the IT personnel. Adaptations that can benefit an entire class or several classes are more likely to be supported and maintained.

Step 2: We regularly identify and evaluate the demands that students are not meeting. The purpose of this step is to define the problem to be addressed by the adaptation and observe students' performance when they use typical instructional materials. They may have difficulty acquiring the important information from written materials, storing or remembering the information presented in the materials, or expressing the information or demonstrating competence in written tests and assignments. If students have difficulty with a given task, different solutions may be required, depending on the level of difficulty and the student's individual needs.

Step 3: We develop goals for teaching strategies and making adaptations. Some problems can be solved by adaptations and other problems may signal the need for intensive instruction in skills or strategies. Often, I may need to provide adaptations while simultaneously teaching the student the learning strategies he or she needs in order to perform the work. All adaptations lead students to become dependent on the person who makes them. Before an adaptation is made for an individual student, I must carefully consider the best approach to addressing the student's difficulty and promoting success. Adaptations should be approached as short-term solutions within a long-term plan for teaching skills and strategies that will promote the student's independence as a learner and ultimately reduce the need for adaptations.

Step 4: We determine whether content or format adaptations are needed. Content adaptations may be made only when we notice that the general curriculum is inappropriate for a particular student. Content adaptations must also meet local and state education standards. Effective adaptations require sustained development and support. They must be made within the framework of a larger plan that includes consideration of (a) basic and strategic skills instruction and (b) the roles of people involved in the adaptation process. In some cases, it is important to involve our Head of Department and curriculum or programme coordinator from the beginning, and identify exactly who will be responsible for making, implementing, supporting and evaluating the adaptation over the course of the year. As much as possible, I involve students and other learning support departments. At our university we use the Centre for Academic Development in order to benefit an entire class, for example in writing for academic purposes.

Step 5: Before we teach, we identify the features of the materials that need to be adapted in order to accommodate all learners. The design of materials can present many different types of problems for students who struggle, but also motivate the fast learners. When we adapt teaching and learning materials we examine each curricular unit for features that might cause a learning problem. For example, the content may be very abstract, complex, or poorly organised, or it might present too much information. It may not be relevant to students or it may be boring. Further, it may call for skills or strategies or background information that the student may not possess. It may present activities that do 
not lead to mastery, or it may fail to give students cues about how to think about or study the information. Materials also may not provide a variety of flexible options through which students can demonstrate competence. Guidelines for identifying these and other problems in the design of instructional materials may be found in resources that are available in the library.

Step 6: We always determine the type of adaptation that will enable the student to meet the teaching and learning demand once the materials have been evaluated and returned.

It is important to note that the methods or strategies described above to accommodate all students are not exclusive. Different teachers use different strategies depending on their competences, effectiveness, conditions and the contexts within which they teach.

\section{Conclusion}

The preceding discussion indicates that we are able use a variety of instructional strategies and learning activities in order to accommodate all learners in our classrooms. The aim is to provide the students with a variety of opportunities to learn in ways that are responsive to their own communication styles, cognitive styles and aptitudes, as prescribed by Gardner (1999) on multiple intelligences. The variety of teaching strategies helps them to develop and strengthen different approaches to learning, some even individualised. We have alluded to the need to consider students' cultures and language skills when developing learning objectives and instructional activities. We have also pointed out the significance of incorporating learning objectives and intended outcomes for effective delivery and mastery.

Our quest is to provide increased opportunities for high and low achievers to boost their self-esteem, develop positive self-attributes, and enhance their strengths and talents. I strongly believe that learning is socially situated and socially constructed. By engaging our students through communicating expectations, letting them know the classroom rules and verbal participation in lessons, we create intellectual spaces for them to learn in a community of practice. Through providing frequent reviews of the content learned we create feedback loops between the students and ourselves. This also provides space for critical engagement to facilitate independence in thinking and action. Indeed, there are numerous ways and strategies to accommodate all learners. As a result, for us teaching and learning is a continuous process of reflection, action and self-correction, and a collaborative process of learning together in an effort to advance knowledge.

\section{References}

Biggs, J. (1999). Teaching for quality learning at university. Buckingham: Society for Research into Higher Education and Open University Press.

Brady, L. (1995). Curriculum development. (5th ed.) Sydney: Prentice Hall.

Chan, J.C., McDermott, K.B., \& Roediger, H.L. (2007). Retrieval-induced facilitation. Journal of Experimental Psychology General, 135:553-571.

Cross, K. P. (1978). The Missing Link: Implications for the Future of Adult Education. New York: Syracuse University Research Corp. ERIC Document Reproduction Service No. ED 095254.

D'Andrea, V. \& Gosling, D. (2005). Improving teaching and learning in higher education. A whole institution approach. The Society for Research into Higher Education. New York: Open University Press.

Department of Education. (1997). A programme for the transformation of higher education. Education White Paper 3. Pretoria: Department of Education.

Doyle, C. \& Singh, A. (2006).Reading and teaching Henry Giroux. New York: Peter Lang.

Duffy, T. M. \& Kirkley, J. R. (eds.). (2004). Learner-centred theory and practice in distance education. Cases from higher education. London: Lawrence Erlbaum Associates Publishers.

Gardner, Howard (1999). Intelligence Reframed. Multiple intelligences for the 21st century. New York: Basic Books.

Giroux, H. A. (2006). The Giroux Reader. Boulder, Colorado: Paradigm Publishers.

Jonassen, D., Marra, R. \& Palmer, B. (2004). Epistemological development: An implicit entailment of constructivist learning environments. In Seel, N.M. \& Dijkstra, S. (eds.). Curriculum, plans and processes in instructional design. London: Lawrence Erlbaum Associates Publishers.

Knowles, M. (1975). Self-directed learning: A Guide for Learners and Teachers. New York: Association Press.

Louw, A.H., Moloi, K.C. \& Smit, J.J.A.C. 2012. Teaching and learning model. Vaal University of Technology. Vanderbijpark.

Loyens, S., Magda, J., \& Rikers, R. (2008). Self-directed learning in problem-based learning and its relationships with self-regulated learning. Educational Psychology Review, 20: 411-427.

Murray, R \& Brary, E. (2008). The scholarship of teaching and learning in higher education: An evidence-based learning in higher education. Dordrecht: Springer. 
Robbins, S.P., Judge, T.A., Odendaal, A. \& Roodt, G. (2009). Organisational behavior. Global and Southern African Perspectives. Cape Town: Pearson Education.

Rothwell, W. J. (2002). The workplace learner. How to align training initiatives with individual learning competencies. New York: AMACOM.

Shelly, G.B., Gunter, G.A. \& Gunter, R.E. (2010). Teachers discovering computers. Integrating technology and digital media in the classroom. $6^{\text {th }}$ ed. Australia: CENGAGE Learning.

Silverthorn, P. (1999). Jean Piaget's theory of development. [Online] Available: http://chd.gse.gmu.edu/constructivism/Piaget.htm (September 15, 2013)

Steenekamp, K., Botha, G. \& Moloi, K.C. (2012). Sustaining change in a learning organisation. Education Africa Review, 9: 380-384.

Tomlinson, C. A. (1999). The differentiated classroom: Responding to the needs of all learners. The Association for supervision and curriculum development. Alexandria, VA: ASCD.

Olivier, R. (1998). When teaching meets learning: Design principles and strategies for web-based learning environments that support knowledge construction. School of Communications and Multi-media, Edith Cowan University, Australia.

Spady, W. 1994. Choosing outcomes of significance. Educational Leadership, 51:18-23.

Winebrenner, S. (1996). Teaching kids with learning difficulties in the regular classroom. Mineapolis: Free Spirit Publishing.

Willis, J. (2008). Brain-based teaching strategies for improving students' memory, learning, and test-taking success. Review of Research. Childhood Education, 83:31-36.

Entwistle, N. 1987).Understanding classroom learning. London: Hodder and Stoughton. 